\title{
Life cycle assessment of adipic acid production from lignin
}

Corona, Andrea; Biddy, Mary J.; Vardon, Derek R.; Birkved, Morten; Hauschild, Michael Zwicky; Beckham, Gregg T.

\section{Published in:}

Green Chemistry

Link to article, DOI:

$10.1039 / \mathrm{c} 8 \mathrm{gc00868j}$

Publication date:

2018

Document Version

Peer reviewed version

Link back to DTU Orbit

\section{Citation (APA):}

Corona, A., Biddy, M. J., Vardon, D. R., Birkved, M., Hauschild, M. Z., \& Beckham, G. T. (2018). Life cycle assessment of adipic acid production from lignin. Green Chemistry, 20(16), 3857-3866.

https://doi.org/10.1039/c8gc00868j

\section{General rights}

Copyright and moral rights for the publications made accessible in the public portal are retained by the authors and/or other copyright owners and it is a condition of accessing publications that users recognise and abide by the legal requirements associated with these rights.

- Users may download and print one copy of any publication from the public portal for the purpose of private study or research.

- You may not further distribute the material or use it for any profit-making activity or commercial gain

- You may freely distribute the URL identifying the publication in the public portal

If you believe that this document breaches copyright please contact us providing details, and we will remove access to the work immediately and investigate your claim 


\title{
Life cycle assessment of adipic acid production from lignin†
}

\author{
Andrea Corona a,b, Mary J. Biddyb, Derek R. Vardonb, Morten Birkveda, Michael Hauschilda, \\ and Gregg T. Beckhamb
}

\begin{abstract}
Lignin is a heterogeneous, aromatic polymer and one of the main components of plant biomass. Current lignocellulosic biorefineries primarily focus on polysaccharide conversion from biomass, and separate and combust the residual lignin for heat and power. By using lignin only as a fuel, this polysaccharide-centric approach potentially limits the exploitation of biomass feedstocks. In this study, we performed a life cycle assessment (LCA) on an emerging lignin upgrading process, namely the production of bio-based adipic acid from lignin sourced from bioethanol production, relative to the conventional petrochemical production pathway. The LCA predicts an overall lower environmental impact for the bio-based route, primarily due to the utilization of a biorefinery sidestream as feedstock material and in the avoidance of nitrous oxide emissions. Bio-based adipic acid is predicted to lead to $4.87 \mathrm{kgCO}_{2 \mathrm{eq}} / \mathrm{kg}_{\mathrm{AA}}$ greenhouse gas emission impacts, which is a reduction of $62 \%$ to $-78 \%$ compared to conventional adipic acid. Furthermore, results from the sensitivity analysis identify sodium hydroxide utilization and heating needs as the inputs that contribute the largest environmental burden in the bio-based process. Alternative lignin depolymerization processes and development of microbial strains that can tolerate low pH are possible optimization strategies to further improve the environmental profile of bio-based adipic acid. The effects of the LCA modelling assumptions on the environmental profile of bio-based adipic acid are also examined, demonstrating that the electricity footprint and the assumptions made to estimate the effects of diverting lignin from energy to material production play an important role in the model predictions. Lastly, this study highlights that partial lignin conversion to select chemicals in biorefineries may be more environmentally beneficial and could bring larger offset credits than solely producing bio-power through combustion, which is the current biorefinery paradigm for lignin utilization.
\end{abstract}

\section{a. Quantitative Sustainability Assessment, Department of Management Engineering, Technical University of Denmark, Bygningstorvet, 2800, Kgs. Lyngby, Denmark \\ b. National Bioenergy Center, National Renewable Energy Laboratory, Golden CO 80401; \\ Biochemicals / lignocellulose I separations / lignin valorization Email: name \\ $\dagger$ Electronic supplementary information (ESI) available.}

\section{Introduction}

Lignin is a natural amorphous polymer and one of the main constituents, along with cellulose and hemicellulose, of lignocellulosic biomass (15-30\% by weight, $40 \%$ by energy). ${ }^{1}$ However, lignin has received less attention relative to cellulose concerning its valorization. While cellulose and hemicellulose can be depolymerized to their constituent sugars, which can be converted to biofuels or biochemicals, lignin cannot be easily depolymerized and upgraded to chemicals of value. ${ }^{2}$ Hence, current biorefinery practices mostly aim to separate sugars from lignin with a primary objective to maximize the yield of carbohydrates. $^{3,4}$

The current second-generation lignocellulosic biorefinery paradigm slates lignin for combustion to supply energy for the operation of the biorefinery. ${ }^{5}$ However, the amount of energy supplied by the lignin is substantially higher ( $40 \%$ more) than that needed for the biorefining operations. ${ }^{6}$ The excess energy produced by combustion is typically intended to be sold to the grid, providing offset credits to biorefinery operations both in economic $^{6,7}$ and environmental terms. ${ }^{8,9}$ Nevertheless, there is strong interest to find alternative uses for lignin and produce value-added products that exploit its unique aromatic structure. ${ }^{1}$ In the United States, the 2007 US Energy and
Independence Security Act mandates a production of 79 billion liters of lignocellulosic biofuels by 2022, which will in turn produce approximately 62 million metric tons of lignin per year. ${ }^{10}$ Maximizing biomass utilization by converting part of the lignin to value-added products, could further improve the economic and environmental performance of $2^{\text {nd }}$ generation biorefineries. . $^{71}$

In addition, one of the most expensive unit operations of the biorefinery is the boiler due to the large quantities of lignin that potentially could be produced, accounting for about $40 \%$ of the total capital cost. ${ }^{6}$ Lignin combustion, despite the biogenic origin of lignin ${ }^{12}$, can cause emission of other air pollutants to air, mainly Particulate Matter (PM) and Hazardous Air Pollutants (HAP), such as aromatic compounds (e.g. benzene, styrene). ${ }^{13,14}$ Recent studies demonstrated these emissions to be among the most burdensome form of air pollution for second generation biorefineries. ${ }^{13}$ Accordingly, utilizing a portion of the lignin stream for production of value-added products could potentially increase profits and reduce environmental impacts in a synergistic manner, namely by increasing the biorefinery product portfolio and reducing the size of the boiler.

The most substantial challenge regarding lignin valorization remains the heterogeneity of its chemical structure. Lignin is assembled from three phenyl-propanoid monomers, connected by $\mathrm{C}-\mathrm{C}$ and $\mathrm{C}-\mathrm{O}$ bonds. ${ }^{15}$ Lignin valorization to chemicals is quite challenging for numerous reasons, chief among them because depolymerization leads to a large pool of different aromatic compounds, which are difficult to separate and purify. Separation issues and lower yields have typically limited biorefinery technologies aimed at converting lignin to a single value-added chemical. 
To convert lignin to single chemicals, several promising strategies have emerged in the last decade, including multiple catalytic strategies that produce small slates of compounds. ${ }^{16-}$ 21 Additionally, the concept of using microbes to convert aromatic compounds to value-added single molecules, termed "biological funneling" has also been pursued..$^{15}$ In nature, some organisms have evolved pathways that enable them to use lignin-derived aromatic compounds as a carbon source. ${ }^{22}$ Microbial lignin conversion can potentially reduce the need for separation and purification and has been shown to be capable of converting several lignin-derived aromatic compounds to a single intermediate, offering a promising approach to lignin valorization for future biorefineries. ${ }^{23}$

This study aims to evaluate the environmental implications of lignin conversion to adipic acid via three steps: base-catalyzed depolymerization of lignin, biological funneling of ligninderived aromatic compounds to cis,cis-muconic acid, and catalytic hydrogenation of muconic acid to adipic acid. The results are compared to conventional petrochemical adipic acid production. The process model employs concepts described in earlier work ${ }^{1,15,24-27}$ that use a metabolically engineered Pseudomonas putida KT2440 strain to convert lignin-derived aromatics to muconic acid, the intermediate product. Muconic acid is then hydrogenated to adipic acid using a noble metal catalyst. ${ }^{24}$ Following crystallization, the purity level of adipic acid $(>99.8 \%)$ meets the requirements for polymer production (e.g. used in a polycondensation reaction to produce Nylon$6,6){ }^{24,28}$ The product is thus assumed suitable for existing processes downstream in the value chain and can thereby be considered a drop-in chemical. Overall, this study predicts a lower environmental impact profile for bio-based adipic acid, due to the use of a renewable, biorefinery side-stream instead of a fossil-based feedstock, and because of the different production pathway employed for the production of adipic acid.

\section{Materials and Methods}

The material and methods section is divided in two parts. The first section gives an overview of adipic acid production, via conventional and bio-based routes. The second part describes details and assumptions of the LCA model.

\section{Conventional adipic acid production}

The current industrial process for adipic acid production is a two-step process that utilizes cyclohexane and nitric acid. During the last reaction (see Eq. 1), part of the $\mathrm{HNO}_{3}$ is converted to $\mathrm{NO}, \mathrm{NO}_{2}$, and $\mathrm{N}_{2} \mathrm{O}$. Some $\mathrm{HNO}_{3}$ can be recycled from $\mathrm{NO}$ and $\mathrm{NO}_{2}$. Conversely, $\mathrm{N}_{2} \mathrm{O}$ is a by-product of the reaction because it cannot be recovered. The stoichiometric emission factor for $\mathrm{N}_{2} \mathrm{O}$ production is $0.3 \mathrm{~kg}$ of $\mathrm{N}_{2} \mathrm{O} / \mathrm{kg}_{\text {AAA. }}$.

$$
\begin{aligned}
& \left(\mathrm{CH}_{2}\right)_{5} \mathrm{CO}+\left(\mathrm{CH}_{2}\right)_{5} \mathrm{CHOH}+\mathrm{wHNO}_{3} \rightarrow \\
& \mathrm{HOOC}\left(\mathrm{CH}_{2}\right)_{4} \mathrm{COOH}+x \mathrm{~N}_{2} \mathrm{O}+y \mathrm{H}_{2} \mathrm{O}(1)
\end{aligned}
$$

Since 1990, several emissions reduction strategies have been established to reduce the emission of $\mathrm{N}_{2} \mathrm{O}^{29}$, due to its substantial greenhouse gas effects $(298 \mathrm{~kg} \mathrm{CO} 2 \mathrm{eq} / \mathrm{kg})$. The most commonly used emission-abatement strategy is thermal destruction, which allows for a reduction of up to $97 \%-99 \%$ of the total $\mathrm{N}_{2} \mathrm{O}$ emissions. ${ }^{30}$ Thermal destruction is the combustion of off-gases (including $\mathrm{N}_{2} \mathrm{O}$ ) in the presence of methane. $\mathrm{N}_{2} \mathrm{O}$ abatement technology is applied in the US and
Europe, while around $15 \%$ of the global production comes from plants without any emission abatement, mainly located in China and Ukraine. ${ }^{31}$ More details on conventional adipic acid production can be found in the Supporting Information (SI) and the $\mathrm{N}_{2} \mathrm{O}$ abatement capacities, as used in this study, are presented in Table S1.

\section{Bio-based adipic acid production}

The production of adipic acid from lignin is a proposed hybrid biological and chemical process, comprising lignin depolymerization, biological conversion, and catalytic hydrogenation. Lignin is sourced from the solid residue after ethanol fermentation in a lignocellulosic biorefinery. This residue is dubbed high lignin fermentation by-product (HLFB). The production can be divided in four major steps:

- The HLFB is depolymerized into aromatic compounds. In this study, depolymerization is achieved by a base catalyzed depolymerization process (BCD). ${ }^{32}$

- Via an engineered strain of $P$. putida, the aromatic compounds are converted to a single intermediate: $c i s, c i s-$ muconic acid.

- Muconic acid is separated from the broth by $\mathrm{pH}$-shift driven crystallization.

- Muconic acid is subsequently catalytically hydrogenated to adipic acid.

\section{Deconstruction}

The HLFB is separated in the biorefinery beer column and sent to the BCD tank for the depolymerization process. Multiple techniques are available to depolymerize lignin ${ }^{7}$, e.g. catalytic depolymerization in aqueous or organic media ${ }^{33}$, high severity alkaline processes ${ }^{32,34}$, hydrogenolysis over catalysts in the presence of high pressures of $\mathrm{H}_{2}$ or hydrogen donors ${ }^{21,35}$. This study used the BCD process to break down lignin into smaller aromatic compounds. ${ }^{7,32}$ In the deconstruction tank, sodium hydroxide $(\mathrm{NaOH})$ is added at $2 \%$ wt per load and steam is applied to increase the temperature to $160^{\circ} \mathrm{C}$. In the alkaline conditions modeled in this study, lignin and other residuals are depolymerized at a conversion extent of $70 \%$ wt of the total solid. After the BCD process, the HLFB is filtered. The liquid stream is sent to the bioreactor, while the residual solids are sent to the boiler. The composition of the HLFB is presented in Table 1. Additional details used for the process simulation are available in Table S2-S4.

Table 1. Assumed composition for the HFLB delivered to the BCD tank. 6,7

\begin{tabular}{ll}
\hline Component & Composition (\% dry wt) \\
\hline Lignin & 51.50 \\
Cellulose & 5.18 \\
Xylan & 1.75 \\
Protein & 17.67 \\
Ash & 16.96 \\
Extractives & 6.94 \\
Moisture (bulk \% wt) & 33 \\
\hline
\end{tabular}

\section{Biological cultivation}

In the bioreactor, $P$. putida is inoculated into the liquid stream for biological conversion. $P$. putida has been identified as one of the most suitable organisms to date for lignin bioconversion, ${ }^{25}$ and has been metabolically engineered to funnel aromatic compounds to catechol, which is oxidatively 
ring opened to cis,cis-muconic acid. When the deconstructed lignin compounds are converted to cis,cis-muconic acid, the medium acidifies in stoichiometric amounts. For each mol of cis,cis-muconic acid produced, 2 mol of $\mathrm{NaOH}$ must be incorporated to maintain the bioreactor at $\mathrm{pH}$ 7. Cis, cismuconic acid is primarily deprotonated to its salt form in water at $\mathrm{pH} \mathrm{7,} \mathrm{which} \mathrm{is} \mathrm{soluble.} \mathrm{Other} \mathrm{inputs} \mathrm{in} \mathrm{this} \mathrm{process} \mathrm{are} \mathrm{the}$ nutrients required for bacterial growth, diammonium phosphate (DAP) and corn steep liquor (CSL). Biological cultivation is performed in a pH-stat fed-batch bioreactor at $32^{\circ} \mathrm{C}$ and 1 bar. Cis,cis-muconic acid is accumulated at a molar yield close to $100 \%$ and a titer of $40 \mathrm{~g} / \mathrm{L}$, in line with previous studies. ${ }^{24,36}$ Additional details used for the process simulation are available in Table S5.

\section{Separation}

After a solid/liquid filtration step, the broth is sent to the crystallizer. Muconic acid is separated from the broth by $\mathrm{pH}-$ shift. cis,cis-Muconic acid readily precipitates at a $\mathrm{pH}$ below its second $\mathrm{pKa}$ value of $3.03 .{ }^{36}$ Sulfuric acid is used as an acidifying agent. $\mathrm{pH}$-shift driven crystallization is performed at a temperature of $5^{\circ} \mathrm{C}$ and pressure of $1 \mathrm{~atm}$. The crystallized muconic acid is recovered via centrifugation. The $\mathrm{pH}$ of the residual broth is then neutralized by $\mathrm{NaOH}$ addition, before being recycled via anaerobic digestion in the wastewater treatment portion of the biorefinery. The resulting sodium sulphate is separated and landfilled. Additional details are available in Table S6.

\section{Catalytic upgrading}

Crystallized muconic acid is dissolved in ethanol and sent to the hydrogenation reactor. Hydrogen is supplied to the reactor and catalytic hydrogenation is performed at 33 bar and $75^{\circ} \mathrm{C}$. The catalyst used in this reaction is $\mathrm{Rh} / \mathrm{C} .{ }^{24}$ Adipic acid is subsequently crystallized at $10^{\circ} \mathrm{C}$. The conversion efficiency of this reaction is assumed to be stoichiometric. Part of the hydrogen (48\%) and ethanol (99.23\%) can be recycled within the catalytic system. The achieved purity is assumed to exceed
$99.8 \%$, hence meeting the requirements for polymer production. ${ }^{24,28}$ Additional details are available in Table S7.

\section{Environmental assessment}

The environmental assessment was conducted by applying the LCA methodology. LCA is considered the most comprehensive methodology for environmental assessments because of its holistic assessment approach and capability of yielding results across different environmental impact categories, thereby providing a broad assessment of environmental burdens and benefits for a product or system. LCA is described in the ISO 14000 and 14040 series standards ${ }^{37,38}$ and is composed of four steps: goal and scope definition, life cycle inventory, impact assessment, and interpretation. ${ }^{39}$

\section{Goal and scope}

The goal of this study is to compare the production of adipic acid from lignin to the conventional fossil-based route. The lignin feedstock used for bioconversion is sourced from a lignocellulosic biorefinery producing ethanol, ${ }^{6,40}$ which instead of utilizing it for energy production, converts it to adipic acid. Due to the large-scale consequences and the aim of this study, which is to provide decision support to biorefinery developers, this study utilizes the consequential LCA approach. ${ }^{41}$ The system boundaries of this LCA includes all steps until the adipic acid gate and the consequences of the avoided lignin combustion. The bio-based and conventional adipic acid are compared at this level. Use and disposal are excluded because bio-based adipic acid is assumed to be functionally equivalent to its conventional counterpart. Furthermore, adipic acid has a large number of uses and applications making it impossible to identify a single use and disposal fate. ${ }^{42}$ The system boundaries are presented in Figure 1. The functional unit of the study is production of $1 \mathrm{~kg}$ of adipic acid with a purity of $>99.8 \%$ (polymer grade). Biogenic carbon is accounted based on Pawelzik et al. ${ }^{43}$ The effects of carbon storage ${ }^{44}$ are excluded because of uncertainties pertaining the lifetime and application of the product.

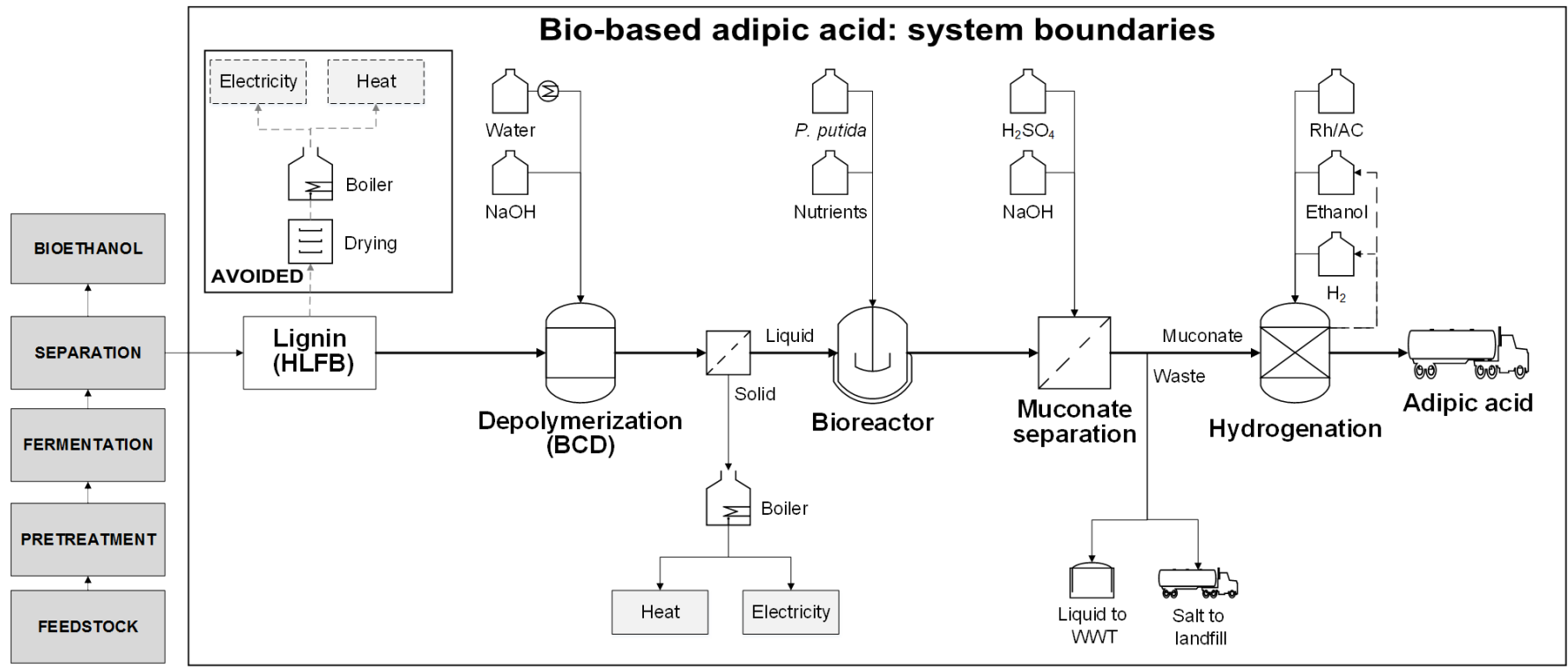

Figure 1. System boundaries of the LCA study. System boundaries start from the separation of the lignin from the main biorefinery stream to the production of adipic acid, at the plant gate. System boundaries are expanded to include the avoided lignin combustion in the biorefinery boiler.

Life cycle inventory 
The inventory data for the bio-based production route are obtained from a process simulation built in AspenPlus to design the industrial $\mathrm{n}^{\text {th }}$-plant production process. ${ }^{6}$ AspenPlus was used to calculate process yields, internal energy demands, and consumption of auxiliary materials needed for the conversion process. The LCA product system model was built with a modular approach by dividing the biorefinery into each one of its unit processes. The approach is capable of calculating the cumulative environmental performance at each production stage in the conversion pathway. As described in Karka et al., this approach facilitates transparency of the impact assessment of bio-based products..$^{45}$ Furthermore, it enhances the ability to assess complex biorefinery systems and identifies critical parameters for each production stage, providing useful information to technology developers at an early stage of the design process. ${ }^{45}$ For the background processes, data sources include EcoInvent $3.1,{ }^{46}$ the GREET database,${ }^{47}$ the USLCI database, ${ }^{48}$ and literature parameters where listed, which are adapted to the case studied.

\section{$\mathrm{N}_{2} \mathrm{O}$ emission in the conventional production process}

A specific inventory model was developed for the conventional route, since the life cycle inventory data for adipic acid production are only available in EcoInvent. However, the inventory is outdated and does not represent current practices and abatement technologies. ${ }^{49,50}$ In order to model the conventional production route, inventory data for cyclohexane and nitric acid production were taken from the EcoInvent database. The adipic acid production process is based on Wang et al.$^{51}$ Emissions of $\mathrm{N}_{2} \mathrm{O}$ were calculated based on the latest IPCC report and their specific guidelines on Greenhouse gases emissions (GHGs) accounting for nitric and adipic acid production. ${ }^{52}$ Two different scenarios were developed for conventional adipic acid production (Table 2): CONV-AAUS, representing adipic acid production in the United States with the most recent $\mathrm{N}_{2} \mathrm{O}$ abatement technologies $(97 \%)$ and CONV-AA-WORLD representing an "average" adipic acid production with the world average abatement capacity ( $85 \%)$. The SI contains more details on the conventional AA module and the methods used to account for $\mathrm{N}_{2} \mathrm{O}$ emissions.

\section{Feedstock impacts}

To evaluate the environmental burdens related to utilizing lignin as a feedstock, previous LCA studies utilized the "zeroburden" approach, which assumes that lignin is a waste stream in lignocellulosic biorefineries and therefore its use incurs zero impact (i.e. lignin is made available by discounting any upstream environmental burden). ${ }^{36}$ Other studies rely on questionable allocation keys to divide the upstream impacts between main biorefinery product and lignin. ${ }^{53,54}$ ISO 14044 describes a hierarchical approach on how to deal with multifunctional processes, favoring subdivision of the multifunctional process if possible, applying system expansion, or as a last resort, using allocation and identifying an allocation key that represents the physical-causality relationship between the co-products. ${ }^{37}$ Since subdivision is not applicable in our study, system expansion is applied to include the consequences of exploiting the HFLB stream for chemical production instead of energy production. The system boundaries are thereby

Table 2. Overview of the different scenarios developed for AA production expanded to account for the avoided energy production and the avoided stack emissions that result when lignin is not combusted but used as feedstock material for bio-based adipic acid. The avoided energy is based on the LHV of the HFLB stream. ${ }^{6}$ Boiler efficiency, heat, and electricity production shares are based on the NREL design report. ${ }^{6}$ The marginal energy deficiency from avoided energy production is assumed to be compensated by natural gas burned in a biogas turbine. ${ }^{12,55}$ The avoided stack emissions from lignin combustion are calculated from Baht et al. ${ }^{14}$ Detailed Life Cycle Inventory (LCI) for the lignin feedstock are in Table S8 and Table S9.

\section{Life cycle impact assessment method}

The Life Cycle Impact Assessment (LCIA) method used in this study is TRACI 2.1 Midpoint. ${ }^{56}$ TRACI has been selected because it is suited for the US scenario, it can provide results across ten different impact categories (ICs), and it does not rely on a single indicator (e.g. GHG emissions). Comparative results between the studied scenarios have been calculated by applying the normalization factor developed by Ryberg et al. ${ }^{57}$ Normalization allows for a common reference for the calculated impacts. TRACI normalization factors relate impact scores to the average yearly impacts of a US or Canadian citizen (2008 for US, 2005 for CA). In the present study, US-2008 factors were used for the normalization step.

\section{Sensitivity analysis}

To evaluate alternative locations and assumptions of the LCA model, different scenarios were developed. Table 2 lists the different scenarios evaluated. The following assumptions were tested in the sensitivity analysis:

- Feedstock: In the baseline scenario, the reduced energy production due to the avoided lignin combustion is substituted by natural gas combusted in the biorefinery boiler. Three additional scenarios were developed to investigate the effects of the modelling assumption developed for the feedstock impact on the total LCA impact score. The first (BIO-AA-F1) applies a zero-burden approach, where no upstream impacts are attributed to the lignin (i.e. lignin, being a waste product, has no impacts). The second (BIO-AA-F2) assumes that the avoided heat production from the avoided combustion of lignin is replaced by NG in the boiler, while the avoided electricity production is supplied by electricity from the Midwest US grid. The amount of lignin combusted in bioethanol refineries is larger than the internal energy need. The excess is used to produce electricity, which is sold to the grid. In the third scenario (BIO-AA-F3), diverting lignin for AA production implies that electricity from the grid replaces the energy not produced by the lignin. Hence, for this last scenario import of grid electricity replaces all the energy not produced by the lignin.

- Location: the biorefinery is assumed to be located in Denmark (contrary to the baseline in the Midwest USA) to evaluate the influence of the background energy mix on the total environmental score. 


\begin{tabular}{|c|c|c|c|c|c|c|}
\hline Product system model description & Acronym & Feedstock & Location & $\begin{array}{c}\mathrm{N}_{2} \mathrm{O} \\
\text { capture }\end{array}$ & $\begin{array}{c}\text { Replacement of } \\
\text { avoided } \\
\text { electricity }\end{array}$ & $\begin{array}{c}\text { Replacement } \\
\text { of avoided } \\
\text { heat }\end{array}$ \\
\hline Conventional AA with highest $\mathrm{N}_{2} \mathrm{O}$ capture & CONV-AA-US & Oil/NG & US & $97 \%$ & - & - \\
\hline $\begin{array}{l}\text { Conventional AA with world average } \mathrm{N}_{2} \mathrm{O} \\
\text { capture }\end{array}$ & CONV-AA-AVG & Oil/NG & World & $85 \%$ & - & - \\
\hline Bio-based AA produced in US & BIO-AA-US & Lignin & US & - & NG & NG \\
\hline Bio-based AA produced in DK & BIO-AA-DK & Lignin & DK & - & NG & NG \\
\hline Bio-based AA with feedstock scenario 1 & BIO-AA-F1 & Lignin & US & - & 0 & 0 \\
\hline Bio-based AA with feedstock scenario 2 & BIO-AA-F2 & Lignin & US & - & $\begin{array}{c}\text { Electricity import } \\
\text { (MW/US-mix) }\end{array}$ & NG \\
\hline Bio-based AA with feedstock scenario 3 & BIO-AA-F3 & Lignin & US & - & $\begin{array}{c}\text { Electricity import } \\
\text { (MW/US-mix) }\end{array}$ & - \\
\hline
\end{tabular}

\section{Results}

Normalized results for the production of $1 \mathrm{~kg}$ of adipic acid This section presents the LCA results comparing the production of adipic acid with the bio-based and the fossil-based route. Figure 2 shows the normalized LCA results for the production of $1 \mathrm{~kg}$ of adipic acid. Midpoint LCA results are presented in Table S6. From Figure 2, almost all ICs are predicted to exhibit impacts of similar magnitude, except for the ozone depletion IC, which has negligible impact potentials (two orders of magnitude lower) compared to other ICs. Emission of stratospheric ozone-depleting substances is limited in the product studied; hence, the contribution to this IC is limited.

With the exception of the respiratory effects IC, BIO-AA-US has lower impacts across all ICs, compared to fossil-based adipic acid. The highest impact reduction is achieved for the Smog IC, where a reduction of approximately $88 \%$ is observed. CONV-AA-US and CONV-AA-AVG have a high impact score in this IC, due to the unabated emission of $\mathrm{NO}$ and the production and use of nitric acid. Hence, the conversion pathway used in BIO-AA-US leads to large savings in this IC. The next largest reduction in impacts is observed for the greenhouse gas emissions, where BIO-AA-US leads to 4.87
$\mathrm{kgCO}_{2 \mathrm{eq}} / \mathrm{kg}_{\mathrm{AA}}$, which is a reduction of $-62 \%$ compared to CONV-AA-US and $-78 \%$ relative to CONV-AA-AVG. Regarding conventional AA, the effects of unabated $\mathrm{N}_{2} \mathrm{O}$ and NO emissions cause burdens in four ICs:, smog, acidification, eutrophication, and respiratory effects. The estimated greenhouse gas emissions are largely affected by the uncaptured $\mathrm{N}_{2} \mathrm{O}$ emissions, due to the high contribution of $\mathrm{N}_{2} \mathrm{O}$ in this impact category. The contribution of $\mathrm{N}_{2} \mathrm{O}$ emissions to the total GHGs potential impacts ranges from $28 \%$ for AACONV-US to $59 \%$ for AA-CONV-AVG. Increasing the abatement capacity from $85 \%$ to $99 \%$ for conventional adipic acid production reduces the potential impacts on GHGs by $43 \%$. Detailed LCA results for biobased and conventional AA are in Table S10-S12.

For the smog, acidification, eutrophication, and respiratory effects ICs, the main contributors are the non-abated emissions of NO. The impacts contribution of NO in the affected ICs for scenario CONV-AA-US and CONV-AA-AVG are similar. In the CONV-AA-AVG scenario, NO emissions have a slightly lower contribution of $69 \%$ for the smog impacts, $51 \%$ of the acidification impacts, and $45 \%$ of the eutrophication impacts. For the other impact categories, the two conventional scenarios have a similar impact score, differing by no more than $4 \%$.

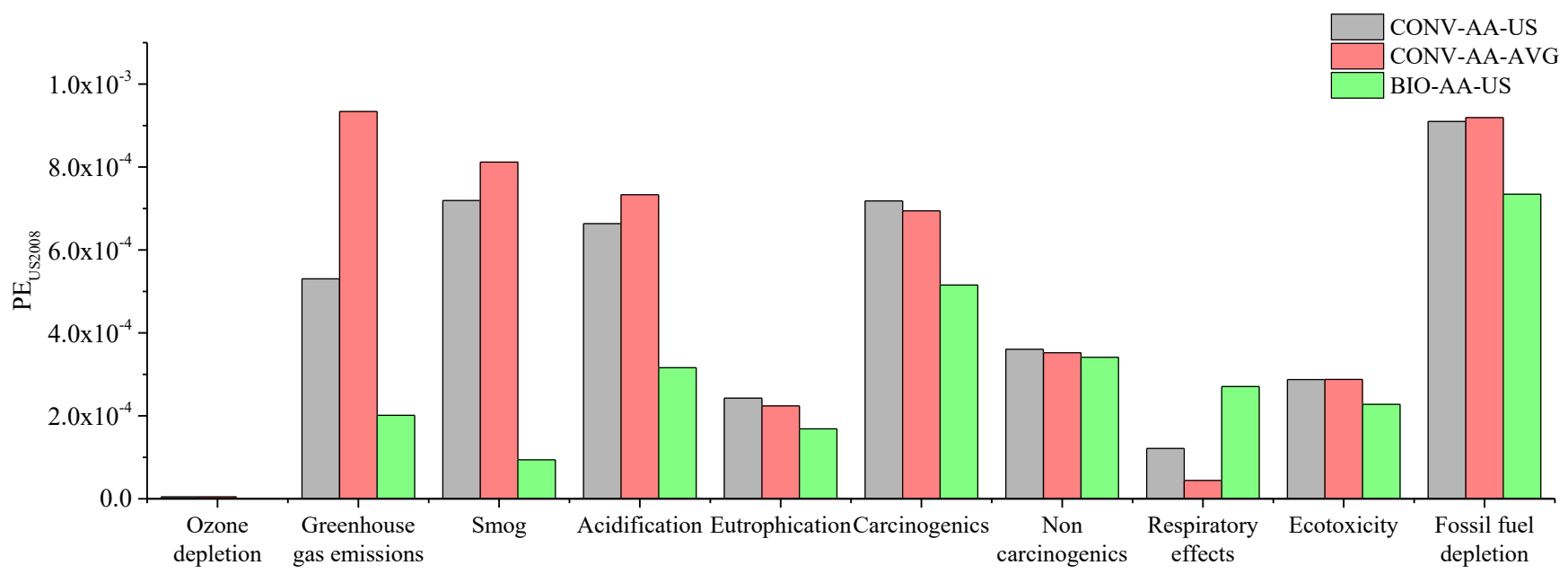

Figure 2. Normalized LCA results for the production of $1 \mathrm{~kg}$ of adipic acid. Results are normalized using the TRACI normalization factor for US ${ }^{57}$ and expressed in person equivalent (PEus2008).

Focus point analysis

This section presents the hotspot analysis results for the BIOAA-US scenario. In Figure 3, the total score is divided showing the contribution of the HFLB and each conversion step, while Figure 4 shows the contribution of each input to the conversion process. The detailed input contribution for each conversion 
step is presented in Table S13-S17. In the following paragraphs, each conversion step is analyzed separately to identify hotspots within each process stage and its contribution to the total impact score. From examination of the feedstock contributions, it is clear that credits, i.e., the negative-impact contributions to the ozone depletion, smog, and noncarcinogenic ICs arise from diverting the use of lignin from combustion to feedstock in the AA process. This is due to avoided stack emissions when diverting lignin slated for combustion. GHG emissions credits are mainly associated with biogenic carbon in the lignin. Avoided ash disposal and lime consumption for flue gas desulfurization of the lignin boiler have negligible impact contributions to this process. The consumption of natural gas, burned to supply the required makeup energy carries all the induced burdens on the other ICs.

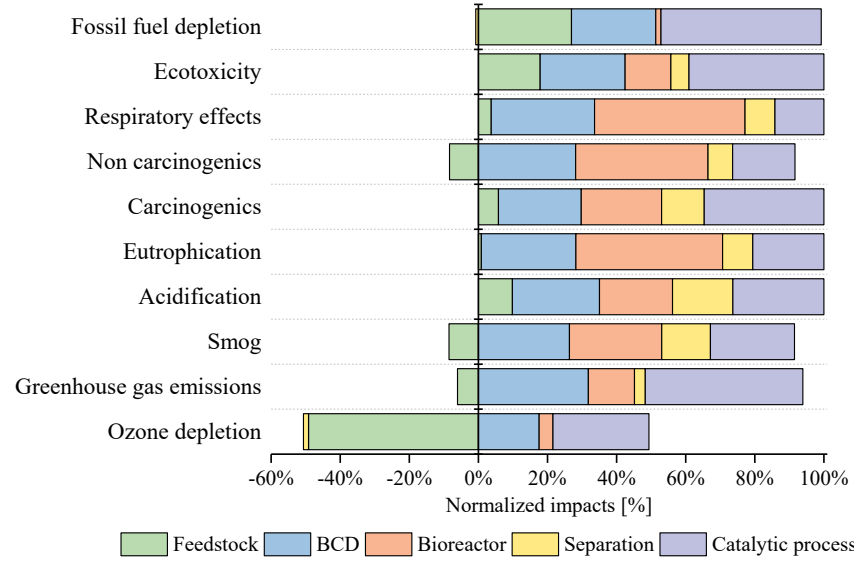

Figure 3. Hotspot analysis results. The contribution of each conversion stage on the total impact score for each ICs is shown.

The $\mathrm{BCD}$ process is predicted to incur large burdens within the smog and acidification ICs, respectively, with $32 \%$ and $25 \%$ of the total impact score. The use of $\mathrm{NaOH}$ and the steam consumption for heating are responsible for most of the impacts, contributing more than $85 \%$ of the total score for this process in every IC. The biological conversion induces considerable impacts amounting to $32 \%, 42 \%, 46 \%$, and $44 \%$ of the total impact score to the smog, eutrophication, noncarcinogenics, and respiratory effects ICs, respectively. The consumption of $\mathrm{NaOH}$, which is used for $\mathrm{pH}$ control in this process, induces most of the environmental burden, contributing more than $60 \%$ to the total score in every IC.

The separation stage is less burdensome compared to the other conversion stages. For this process, the most burdensome input is sulfuric acid, which is used to acidify the solution to induce crystallization of muconic acid. This input carries more than $75 \%$ of the impacts in every IC except for GHG emissions and fossil depletion. The production of biogas in the wastewater treatment step leads to minor savings. However, the magnitude of the savings is small compared to the total score of each IC due to the low amount of volatile solid available in the waste stream and the burdens of the wastewater treatment itself. The largest savings for this step can be observed for the fossil fuel depletion and ozone depletion ICs. Catalytic upgrading has a large contribution to greenhouse gas emissions, acidification, carcinogenics, ecotoxicity, and fossil fuel depletion respectively $52 \%, 26 \%, 35 \%, 39 \%$, and $47 \%$ of the total impact score, mainly connected to the direct material and energy input to the catalytic process, i.e., the catalyst, process energy, and ethanol recycling.

Figure 4 shows that the most environmentally taxing activities for the whole biorefining process are the use of $\mathrm{NaOH}$ and the heating duties. $\mathrm{NaOH}$ is predicted to incur the highest contributions in the smog, eutrophication, carcinogenics, noncarcinogenics, and respiratory effect ICs, constituting $46 \%$, $60 \%, 34 \%, 71 \%$, and $54 \%$ of the total impact score, respectively. Heating duties contribute more significantly to the greenhouse gas emissions, ecotoxicity, and fossil fuel depletion ICs, with $58 \%, 35 \%$, and $51 \%$ of the total impact score, respectively. The $\mathrm{BCD}$ process requires large inputs of $\mathrm{NaOH}$, with $38 \%$ of the total $\mathrm{NaOH}$ input added during lignin depolymerization, $62 \%$ used to as buffer in the bioreactor, and the remaining $1 \%$ added in the separation step. Heat consumption occurs during the $\mathrm{BCD}$ process for the depolymerization reaction and during the muconic acid hydrogenation process.

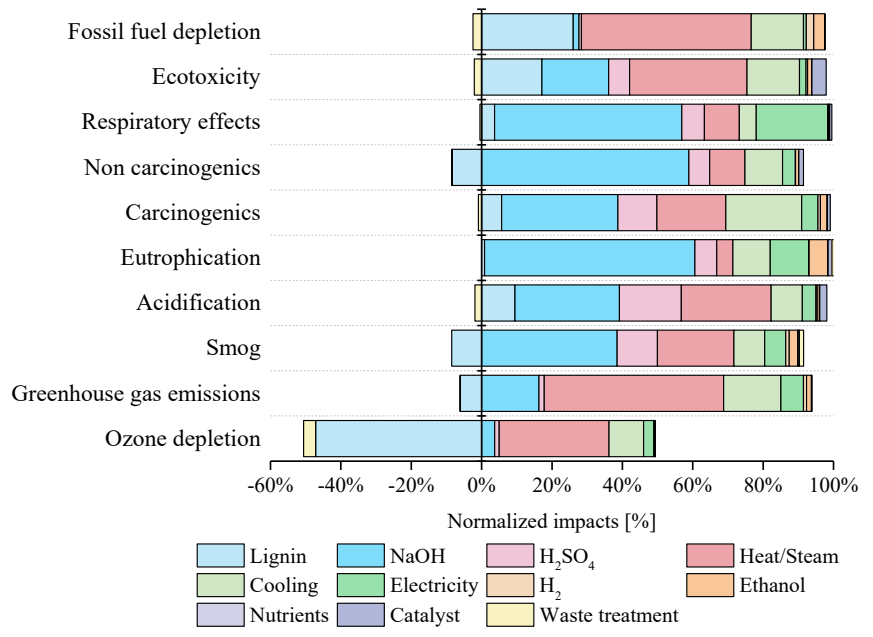

Figure 4. Hotspot analysis results. The contribution of process input on the total impact score for each ICs is shown.

\section{Impact of geographical location}

In this section, the effects of geographical location on the environmental profile of the bio-based AA are quantified. Figure 5 presents the scenario analysis results focusing on the biorefinery location. The largest variation due to the biorefinery location is connected with the environmental footprint of the electricity consumed by the plant. The Danish electricity mix, with a higher share of renewables and lower share of electricity from coal, is predicted to exhibit reductions to the environmental impact for the BIO-AA-DK scenario compared to the BIO-AA-US scenario, as expected. The largest impact reduction can be seen for the acidification, respiratory effects, and ecotoxicity ICs, with $-36 \%,-31 \%$, and $-48 \%$, respectively. For the other ICs, the reduction is lower and no more than $-15 \%$ of the total impact. The largest impact reduction is achieved for the ICs affected the most by emissions due to coal combustion for electricity production, such as acidification, ecotoxicity, and respiratory effects. This is due to the fact that electricity from coal accounts for approximately $63 \%$ of the MW/US grid mix, while it is only $22 \%$ of the Danish grid mix. ${ }^{46}$ Only fossil fuel depletion shows a slight increase in impacts in the Danish scenario $(+5 \%)$. This is due to the use of natural gas for electricity production, which has a high characterization factor 
in this IC. Electricity production from natural gas has a higher share in the Danish than the US energy mix.

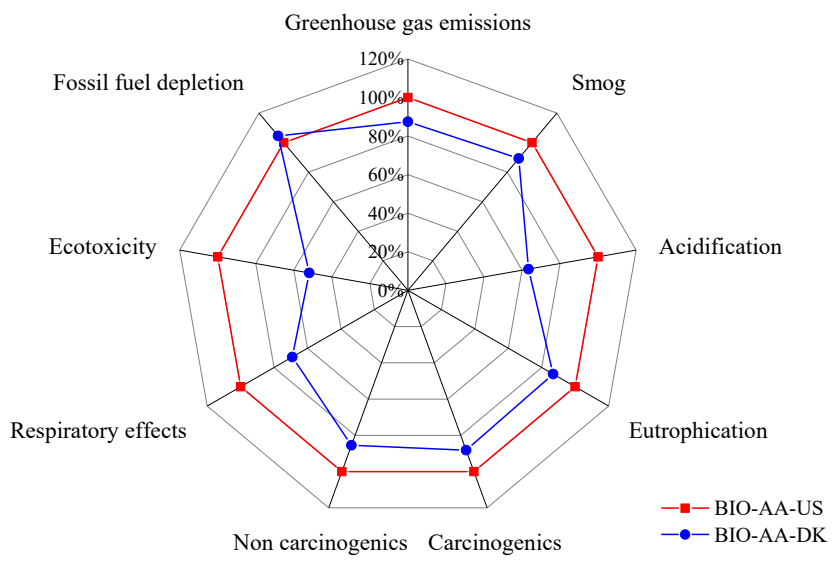

Figure 5. Scenario analysis results demonstrating the effect of the geographical location of the biorefinery on the LCA results.

Product system modelling approach for the feedstock impacts

In this section, the effect of modelling assumptions related to diverting the HFLB from energy production in the bioethanol biorefinery to AA production are examined. Table 3 presents the midpoint results for the production of $1 \mathrm{~kg}$ of AA using different feedstock scenarios. By not accounting for any upstream impacts of lignin utilization, BIO-AA-F1 (i.e. the zero-burden approach), yields the lowest environmental impact score for most ICs. The largest reduction, in comparison to the baseline, is observed for the GHG emissions $-30 \%$ and fossil fuel depletion $-27 \%$ ICs. This is largely a result of not accounting for the missing energy production due to diverting lignin, which in the other scenarios is supplied in different ways, i.e., natural gas or grid electricity. However, for smog and non-carcinogenics, the zero-burden approach shows a slightly higher impact score than the baseline $(+10 \%$ for both ICs) because the avoided stack emission from burning the lignin is not taken into consideration. BIO-AA-F3, on the other hand, shows the highest impact potential compared to the other feedstocks scenarios for most ICs. The ICs most affected in this scenario are respiratory effects, $+291 \%$ compared to the baseline, eutrophication, $+162 \%$, and smog, $+106 \%$. The impact scores increase by approximately $+50 \%$ for the other ICs compared to the other scenarios except for fossil fuel depletion. BIO-AA-F2 is based on the assumption that a part of the energy is supplied by NG and part by electricity from the grid, and this scenario has an impact score somewhere between the baseline and BIO-AA-F3. 
Table 3. Scenario analysis results. Results are shown for the production of $1 \mathrm{~kg}$ of AA with the different modelling approaches to estimate the feedstock impacts. Specifically, BIO-AA-US is the baseline scenario, in BIO-AA-F1 the zero-burden approach is used, in BIO-AA-F2 natural gas is burned to supply the heat while electricity is supplied by the grid, and in BIO-AA-F3 all the missing energy is supplied by electricity from the grid.

\begin{tabular}{|c|c|c|c|c|c|}
\hline Impact category & Unit & BIO-AA-US & BIO-AA-F1 & BIO-AA-F2 & BIO-AA-F3 \\
\hline Ozone depletion & $\mathrm{Kg} \mathrm{CFC}_{11 \text {-eq }}$ & $-1.11 \times 10^{-8}$ & $4.20 \times 10^{-07}$ & $-4.55 \times 10^{-9}$ & $1.58 \times 10^{-8}$ \\
\hline Greenhouse gas emissions & $\mathrm{Kg} \mathrm{CO}_{2 \text {-eq }}$ & $4.87 \times 10^{0}$ & $3.40 \times 10^{0}$ & $5.67 \times 10^{0}$ & $8.16 \times 10^{0}$ \\
\hline Smog & $\mathrm{Kg} \mathrm{O}_{3 \text {-eq }}$ & $1.31 \times 10^{-1}$ & $1.44 \times 10^{-1}$ & $1.64 \times 10^{-1}$ & $2.69 \times 10^{-1}$ \\
\hline Acidification & $\mathrm{Kg} \mathrm{SO}_{2 \text {-eq }}$ & $2.87 \times 10^{-2}$ & $2.59 \times 10^{-2}$ & $3.17 \times 10^{-2}$ & $4.11 \times 10^{-2}$ \\
\hline Eutrophication & $\mathrm{Kg} \mathrm{N}_{\text {-eq }}$ & $3.64 \times 10^{-3}$ & $3.61 \times 10^{-3}$ & $5.08 \times 10^{-3}$ & $9.54 \times 10^{-3}$ \\
\hline Carcinogenics & $\mathrm{CTU}_{\mathrm{h}}$ & $2.72 \times 10^{-8}$ & $2.56 \times 10^{-8}$ & $3.08 \times 10^{-8}$ & $4.18 \times 10^{-8}$ \\
\hline Non carcinogenics & $\mathrm{CTU}_{\mathrm{h}}$ & $3.59 \times 10^{-7}$ & $3.95 \times 10^{-7}$ & $4.05 \times 10^{-7}$ & $5.49 \times 10^{-7}$ \\
\hline Respiratory effects & $\mathrm{Kg} \mathrm{PM}_{2.5}$ & $6.56 \times 10^{-3}$ & $6.32 \times 10^{-3}$ & $1.12 \times 10^{-2}$ & $2.57 \times 10^{-2}$ \\
\hline Ecotoxicity & $\mathrm{CTU}_{\mathrm{e}}$ & $2.52 \times 10^{0}$ & $2.07 \times 10^{0}$ & $2.52 \times 10^{0}$ & $2.53 \times 10^{0}$ \\
\hline Fossil fuel depletion & MJ surplus & $1.38 \times 10^{1}$ & $1.00 \times 10^{1}$ & $1.31 \times 10^{1}$ & $1.08 \times 10^{1}$ \\
\hline
\end{tabular}

\section{Discussion and Conclusions}

This study evaluates the environmental impact profile of adipic acid produced from a lignin waste stream, sourced from a bioethanol biorefinery. This emerging approach has been compared to the conventional fossil-based adipic acid, produced in modern plants with high $\mathrm{N}_{2} \mathrm{O}$ abatement capacity and an "average" adipic acid production, which represents the world average emission abatement capacity. Bio-based adipic acid is predicted to exhibit an improved environmental impact profile than the conventional one for most ICs, mainly because of the use of renewable side-stream as feedstock instead of the conventional fossil-based one, and because of the production pathway, which mitigates all $\mathrm{N}_{2} \mathrm{O}$ emissions. Both aspects are well aligned with the principles of green chemistry. ${ }^{58}$ Furthermore, in an attempt to provide insightful information for process designers, hotspot analysis identified the processes that carry the highest burdens in the bio-based conversion process. Sodium hydroxide consumption and heating duties are the inputs with the highest impacts throughout the conversion process.

In addition, a scenario analysis highlights the effects of the modelling choices and geographical location on the LCA results of the plant. Geographical location has a small overall effect on the environmental profile of the bio-based AA, since it mainly affects the environmental footprint of the gridelectricity demand, which has a minor contribution in comparison to other biorefinery inputs. On the other hand, modelling assumptions for the feedstock have larger effects on the overall results. By not accounting for any upstream impacts, the zero-burden approach tends to discount the utilization of lignin and provides inconsistent LCA results with some of the lowest scores for many ICs. However, using a consequential LCA approach requires that all changes, incurred by the studied product system should be accounted for, which is important in this case especially because the bioethanol refinery receives substantial offset credits via exported electricity from lignin combustion.

Producing bio-based adipic acid from lignin could bring significant environmental benefits, but there is also large room for improvements that could further reduce the environmental impacts including respiratory effects, where conventional production still yields a lower impact potential. We note that the process proposed here has not been fully integrated at the bench scale, and significant improvements remain to be achieved. With the current model assumptions, three focus points for improving further the environmental profile were identified. The first is connected to the depolymerization process. Lignin is highly recalcitrant, requiring harsh chemical conditions to undergo depolymerization for industrial utilization, which subsequently demands for a large consumption of heat and $\mathrm{NaOH}$ which, in this case, is the catalyst used for lignin depolymerization. The process is currently being optimized at bench scale to achieve the highest depolymerization rate. Nevertheless, trade-offs could be realized if lower depolymerization rates were applied, implying lower consumption of energy and auxiliary materials. More importantly, it is noteworthy that many lignin depolymerization strategies exist and are under active development that could likely employ more easily recoverable catalysts or employ high temperature, non-catalytic lignin depolymerization, thus reducing material inputs to the process., ${ }^{1,3}$ The second focus point is on the biological cultivation step. The biological production of an organic acid is problematic since current bacteria strains do not tolerate acid conditions. Hence, the broth must be neutralized continuously to ensure a high productivity rate. This fact drives the consumption of $\mathrm{NaOH}$ and the subsequent production of waste salts. Further process improvements, which would likely have positive environmental outcomes, could be potentially gained in the use of alternative microbes that can more effectively tolerate lower $\mathrm{pH}$ ranges, as identified also by Morales et al. ${ }^{59}$ The third focus point is the catalytic process. In this study, a noble metal catalyst is used for the hydrogenation process. Further process improvements could be gained by using more earth-abundant metals, if they are capable of providing similar catalytic performance. However, it is important to note that although the detailed process improvement suggestions and quantitative environmental metrics are specific to the integrated process examined here, the overall results highlight a positive environmental benefit to bio-based adipic acid from a lignin feedstock relative to petroleum-based adipic acid.

Finally, the modularity of the product system model allows for projecting the environmental benefits that can be achieved in the bioethanol biorefinery, if lignin is used for adipic acid production rather than solely for combustion. The difference 
between bio-based and fossil-based adipic acid provides offset credits for the bioethanol biorefinery. However, a more comprehensive, holistic assessment of lignin utilization, both in terms of environmental and economic aspects, should be applied to compare multiple conversion routes and end products in parallel to the common use of direct combustion of lignin for combined on-site heat and power. Furthermore, future assessments should investigate the optimal share between lignin used to supply the biorefinery energy demands and lignin available for alternative uses, which could also affect the modelling assumptions of the lignin feedstock and boiler capacity.

\section{Acknowledgements}

The study is co-funded by the Bio-Value Platform (http://biovalue.dk/), funded under the SPIR initiative by The Danish Council for Strategic Research and The Danish Council for Technology and Innovation, case no: 0603-00522B. The NREL authors thank the U.S. Department of Energy Bioenergy Technologies Office (DOE-BETO) for funding this work via Contract No. DE-AC36-08GO28308 with the National Renewable Energy Laboratory. The U.S. Government retains and the publisher, by accepting the article for publication, acknowledges that the U.S. Government retains a nonexclusive, paid up, irrevocable, worldwide license to publish or reproduce the published form of this work, or allow others to do so, for U.S. Government purposes. The first author thanks the NREL bioenergy team for the nice working environment, great discussions, and constructive input during his stay there. The views and opinions of the authors expressed herein do not necessarily state or reflect those of the United States Government or any agency thereof. Neither the United States Government nor any agency thereof, nor any of their employees, makes any warranty, expressed or implied, or assumes any legal liability or responsibility for the accuracy, completeness, or usefulness of any information, apparatus, product, or process disclosed, or represents that its use would not infringe privately owned rights.

\section{References}

1 A. J. Ragauskas, G. T. Beckham, M. J. Biddy, R. Chandra, F. Chen, M. F. Davis, B. H. Davison, R. a Dixon, P. Gilna, M. Keller, P. Langan, A. K. Naskar, J. N. Saddler, T. J. Tschaplinski, G. a Tuskan and C. E. Wyman, Science, 2014, 344, 1246843.

2 J. Zakzeski, P. C. a Bruijnincx, A. L. Jongerius and B. M. Weckhuysen, Chem. Rev., 2010, 110, 3552-99.

3 R. Rinaldi, R. Jastrzebski, M. T. Clough, J. Ralph, M. Kennema, P. C. A. Bruijnincx and B. M. Weckhuysen, Angew. Chemie Int. Ed., 2016, 8164-8215.

4 P. Azadi, O. R. Inderwildi, R. Farnood and D. a. King, Renew. Sustain. Energy Rev., 2013, 21, 506-523.

5 S. P. S. Chundawat, G. T. Beckham, M. E. Himmel and B. E. Dale, Annu. Rev. Chem. Biomol. Eng, 2011, 2, 121-45.

6 D. Humbird, R. Davis, L. Tao, C. Kinchin, D. D. Hsu and A. Aden, Process Design and Economics for Biochemical Conversion of Lignocellulosic Biomass to Ethanol Process Design and Economics for Biochemical Conversion of Lignocellulosic Biomass to Ethanol, 2011, vol. 303.

$7 \quad$ R. Davis, L. Tao and E. C. D. Tan, Natl. Renew. Energy Lab., 2013, 147.

8 D. D. Hsu, D. Inman, G. A. Heath, E. J. Wolfrum, M. K. Mann and A. Aden, Environ. Sci. Technol., 2010, 44, 528997.
D. Tonini, L. Hamelin and T. F. Astrup, GCB Bioenergy, 2016, 8, 690-706.

10 M. Langholtz, M. Downing, R. Graham, F. Baker, A. Compere, W. Griffith, R. Boeman and M. Keller, SAE Int. J. Mater. Manuf., 2014, 7, 115-121. W. O. S. Doherty, P. Mousavioun and C. M. Fellows, Ind. Crops Prod., 2011, 33, 259-276.

C. D. Scown, A. A. Gokhale, P. A. Willems, A. Horvath and T. E. McKone, Environ. Sci. Technol., 2014, 48, 84468455.

Y. Zhang, A. Bhatt, G. Heath, M. Thomas, J. Renzaglia, Y. Zhang, A. Bhatt, G. Heath, M. Thomas and J. Renzaglia, Federal Air Pollutant Emission Regulations and Preliminary Estimates of Potential-to-Emit from Biorefineries. NREL/TP-6A20-62547, Golden, CO, 2016. A. Bhatt, Y. Zhang, G. Heath, M. Thomas, J. Renzaglia, A. Bhatt, Y. Zhang, G. Heath, M. Thomas and J. Renzaglia, Federal Air Pollutant Emission Regulations and Preliminary Estimates of Potential-to-Emit from Biorefineries Biomass to Hydrocarbon Fuels. NREL/TP6A20-67333, Golden, CO, 2017.

J. G. Linger, D. R. Vardon, M. T. Guarnieri, E. M. Karp, G. B. Hunsinger, M. a. Franden, C. W. Johnson, G. Chupka, T. J. Strathmann, P. T. Pienkos and G. T. Beckham, Proc. Natl. Acad. Sci., 2014, 111, 12013-12018.

A. Rahimi, A. Ulbrich, J. J. Coon and S. S. Stahl, Nature, DOI:10.1038/nature13867.

17 P. Ferrini and R. Rinaldi, Angew. Chemie - Int. Ed., 2014, 53, 8634-8639.

18 E. M. Anderson, M. L. Stone, R. Katahira, M. Reed, G. T. Beckham and Y. Romá N-Leshkov, DOI:10.1016/j.joule.2017.10.004.

S. Van Den Bosch, W. Schutyser, R. Vanholme, T. Driessen, S.-F. Koelewijn, T. Renders, B. De Meester, W. J. J. Huijgen, W. Dehaen, C. M. Courtin, B. Lagrain, W. Boerjan and B. F. Sels, Energy Environ. Sci., 2015, 8, 1748 1763.

20 T. Renders, S. Van Den Bosch, S.-F. Koelewijn, W. Schutyser and B. F. Sels, Energy Environ. Sci., 2017, 10, 1551-1557.

Q. Song, F. Wang, J. Cai, Y. Wang, J. Zhang, W. Yu and J. $\mathrm{Xu}$, Energy Environ. Sci., 2013, 6, 994.

G. Fuchs, M. Boll and J. Heider, Nat. Rev. Microbiol., 2011, 9, 803-816.

23 G. T. Beckham, C. W. Johnson, E. M. Karp, D. Salvach??a and D. R. Vardon, Curr. Opin. Biotechnol., 2016, 42, 4053.

24 D. R. Vardon, N. A. Rorrer, D. Salvachúa and A. E. Settle, Green Chem.

25 D. Salvachúa, E. M. Karp, C. T. Nimlos, D. R. Vardon and G. T. Beckham, Green Chem., 2015, 17, 4951-4967.

26 D. R. Vardon, M. A. Franden, C. W. Johnson, E. M. Karp, M. T. Guarnieri, J. G. Linger, M. J. Salm, T. J. Strathmann and G. T. Beckham, Energy Environ. Sci., 2015, 8, 617628.

27 C. W. Johnson, D. Salvachúa, P. Khanna, H. Smith, D. J. Peterson and T. Beckham, Metab. Eng. Commun., 2016, 3, 111-119.

28 Radici Group, Technical report: adipic acid, https://www.radicigroup.com/documents/15b7e985-82234453-a193-b1518a5d5bc4 (accessed 02/18/2018).

29 IPCC, 2006 IPCC Guidelines for National Greenhouse Gas Inventories Volume 4 Agriculture, Forestry and Other Land Use, 2006.

30 US-EPA, Global Mitigation of Non-CO2 Greenhouse Gases: 2010-2030, 2013.

31 L. R. Schneider, M. Lazarus and A. Kollmuss, Industrial $N 2 O$ projects under the CDM: Adipic acid - a case of carbon leakage?, Stockholm, 2010. 

Eng., 2008, 85, 906-916.

33 J. Zakzeski, P. C. A. Bruijnincx, A. L. Jongerius and B. M. Weckhuysen, Chem. Rev., 2010, 110, 3552-3599.

34 J. E. Miller, L. Evans, A. Littlewolf and D. E. Trudell, Fuel, 1999, 78, 1363-1366.

35 G. S. Macala, T. D. Matson, C. L. Johnson, R. S. Lewis, A. V. Iretskii and P. C. Ford, ChemSusChem, 2009, 2, 215217.

36 J. B. J. H. Van Duuren and C. Wittmann, Bioprocess. Renew. Resour. to Commod. Bioprod., 2014, 519-540.

37 ISO, Environ. Manag. - Life cycle Assess. - Princ. Framew., 2006, 46.

38 ISO, Environ. Manage., 2006, 3, 28.

39 JRC, ILCD Handb. Int. Ref. Life Cycle Data Syst., 2011, 159.

40 A. Aden, M. Ruth, K. Ibsen, J. Jechura, K. Neeves, J. Sheehan, B. Wallace, L. Montague, A. Slayton and J. Lukas, 53 Natl. Renew. Energy Lab., 2002, Medium: ED; Size: 154 pages.

41 B. P. Weidema, T. Ekvall and R. Heijungs, Guidel. Appl. Deep. broadened LCA. Deliv. D18 Work Packag. 5 CALCAS Proj., 2009, 49.

42 A. Azapagic and H. Stichnothe, in Sustainable Development in Practice, John Wiley \& Sons, Ltd, Chichester, UK, 2010, pp. 142-169.

43 P. Pawelzik, M. Carus, J. Hotchkiss, R. Narayan, S. Selke, M. Wellisch, M. Weiss, B. Wicke and M. K. Patel, Resour. Conserv. Recycl., 2013, 73, 211-228.

44 M. Brandão and A. Levasseur, Assessing temporary carbon storage in life cycle assessment and carbon footprinting, 2011.

45 P. Karka, S. Papadokonstantakis and A. Kokossis, Int. J. Life Cycle Assess., , DOI:10.1007/s11367-017-1262-6.

46 G. Wernet, C. Bauer, B. Steubing, J. Reinhard, E. Moreno-
47

48

49

50

Ruiz and B. Weidema, Int. J. Life Cycle Assess., 2016, 21, $1218-1230$

J. B. Dunn, F. Adom, N. Sather, J. Han and S. Snyder, Argoone Natl. Lab., 2015, 95.

Athena Sustainable Materials Institute, L. Franklin

Associates and Sylvatica, .

H. Althaus, M. Chudacoff, R. Hischier, N. Jungbluth, M.

Osses, A. Primas and S. Hellweg, Final Rep. ecoinvent data ..., 2007, 1-957.

J. B. J. H. Van Duuren, B. Brehmer, A. E. Mars, G. Eggink, V. A. P. M. dos Santos and J. P. M. Sanders, Biotechnol. Bioeng., 2011, 108, 1298-1306.

Q. Wang, I. Vural Gürsel, M. Shang and V. Hessel, Chem. Eng. J., 2013, 234, 300-311.

H. Mainhardt and D. Kruger, IPCC Good Pract Guid. Uncertain. Manag. Natl. Greenh. Gas Invent., 2000, 183195.

I. S. Modahl, A. Brekke and C. Valente, J. Clean. Prod., 2015, 94, 247-259.

I. S. Modahl and I. B. Vold, The 2010 LCA of cellulose, ethanol, lignin and vanillin from Borregaard, Sarpsborg, 2010.

G. Pourhashem, P. R. Adler, A. J. Mcaloon and S. Spatari, Environ. Res. Lett, 2013, 8, 25021-13.

J. Bare, Clean Technol. Environ. Policy, 2011, 13, 687-696. M. Ryberg, M. D. M. Vieira, M. Zgola, J. Bare and R. K. Rosenbaum, Clean Technol. Environ. Policy, 2014, 16, 329-339.

P. T. Anastas and J. C. Warner, Green chemistry: theory and practice, Oxford University Press, 1998.

M. Morales, M. Ataman, S. Badr, S. Linster, I. Kourlimpinis, S. Papadokonstantakis, V. Hatzimanikatis and K. Hungerbühler, Energy Environ. Sci., , DOI:10.1039/C6EE00634E. 


\section{TOC Image}

Figure

Description 